\title{
BMJ Open Association of birth of girls with postnatal depression and exclusive breastfeeding: an observational study
}

\author{
Akanksha Jain, ${ }^{1}$ Prashant Tyagi, ${ }^{1}$ Prabhjeet Kaur, ${ }^{1}$ Jacob Puliyel, ${ }^{1}$ \\ Vishnu Sreenivas ${ }^{2}$
}

To cite: Jain A, Tyagi $P$, Kaur $\mathrm{P}$, et al. Association of birth of girls with postnatal depression and exclusive breastfeeding: an observational study. BMJ Open 2014;4:e003545. doi:10.1136/bmjopen-2013003545

- Prepublication history for this paper is available online. To view these files please visit the journal online (http://dx.doi.org/10.1136/ bmjopen-2013-003545).

Received 18 July 2013 Revised 17 November 2013 Accepted 19 November 2013

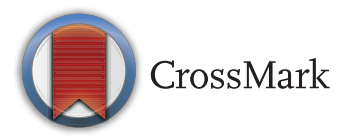

${ }^{1}$ Department of Pediatrics, St Stephen's Hospital, Tis Hazari, Delhi, India

${ }^{2}$ Department of Biostatistics, AIIMS, New Delhi, India

Correspondence to Dr Akanksha Jain; jain.akanksha84@gmail.com

\section{ABSTRACT}

Objectives and hypothesis: To examine the influence of gender of the baby on exclusive breastfeeding and incidence of postnatal depression (PND). We hypothesise that in a society with a male gender bias there may be more PND and less exclusive breastfeeding of the girl child.

Design: Prospective study.

Setting: The study was conducted in an urban, tertiary hospital in Delhi.

Participants: Mothers delivering normally with their babies roomed-in. 1537 eligible women participated in the study.

\section{Primary and secondary outcome measures:}

Exclusive breastfeeding within the first $48 \mathrm{~h}$ of life and score on the Edinburgh Postnatal Depression Scale (EPDS) were recorded.

Results: 3466 babies were born in the hospital. There were 792 girls for every 1000 boys. Among primiparous women, the sex ratio was 901 girls per 1000 boys. For second babies, the sex ratio was 737:1000. If the first child was a girl the birth ratio fell to 632.1026 mothers were exclusively breastfeeding. Exclusive breastfeeding of boys was significantly higher $(70.8 \%$ vs $61.5 \%, p<0.001)$. The EPDS score was significantly higher with the birth of girls (EPDS $6.0 \pm 3.39$ vs $5.4 \pm 2.87, p<0.01$ ). Women with an EPDS score $>11$ were less likely to exclusively breastfeed $(p<0.01)$.

Conclusions: The results point to a pro-male gender bias evidenced by a low sex ratio at birth, higher EPDS score in mothers of girls and less breastfeeding of female children.

\section{INTRODUCTION}

Breast milk is the preferred food for all infants including premature and sick babies. ${ }^{1}$ UNICEF has promoted breastfeeding initiation within an hour of childbirth. ${ }^{2}{ }^{3}$ It provides nutritional, immunological, developmental and psychological advantages to the child besides health advantages to the mother and economic benefits to the family. ${ }^{1}$ It establishes skin-to-skin contact providing

\section{Strengths and limitations of this study}

- Postnatal depression was evaluated using the widely validated Edinburgh Postnatal Depression Scale (EPDS) scoring system.

- It was carried out in an urban hospital catering mostly to a middle-class clientele. The findings on sex ratio may therefore not be generalisable to other social groups.

- We studied the initiation of exclusive breastfeeding in the first $48 \mathrm{~h}$. More studies are needed to elaborate the effect of sex bias on the duration of breastfeeding.

- EPDS scoring was performed in the first $48 \mathrm{~h}$ and would include mothers with transient postnatal blues not amounting to postnatal depression. Follow-up studies are needed to see that how many of them develop significant depression.

- Although multiple regression analysis shows that higher depression score and female sex of the child are associated with lower odds of exclusive breastfeeding, a causal relationship is not implied.

- High rate of sex-selective abortion may complicate the interpretation of results.

warmth to the newborn. Suckling at the breast stimulates oxytocin release which further increases flow of milk from the breast. Breast milk reduces mortality in the first month of life. ${ }^{4}$ Early breastfeed initiation is also associated with increased exclusive breastfeeding (EBF) and longer duration of breastfeeding. ${ }^{5}$ The WHO and UNICEF launched the baby-friendly hospital initiative in 1991 to strengthen maternity unit practices to support breastfeeding. ${ }^{6}$ However in spite of all these promotions and the known benefits of breastfeeding, EBF and early initiation of breastfeeding are not often practiced. Factors intrinsic to the mother or baby may play a crucial role. One such factor is postnatal depression (PND) and there is evidence that mothers with PND are less likely to breastfeed. ${ }^{78}$ 
Expression of PND may extend from the more transient baby blues to a longer lasting depression going on for several weeks. ${ }^{9}$ In both conditions there are mood swings, crying jags, sadness, insomnia and irritability. ${ }^{10} 11$

The 10-question Edinburgh Postnatal Depression Scale (EPDS) is a validated, valuable and efficient way of identifying patients at risk for perinatal depression. It can be applied for depression screening during pregnancy. ${ }^{12}$ The scale has been used as early as the first or second postnatal day by Teissèdre in order to screen women at risk of PND. In his study, 1154 women completed the EPDS at 2-3 postnatal days and again at 46 weeks postnatal. He found that there was a highly significant positive correlation between EPDS scores on the two occasions (Spearman rank correlation $\mathrm{r}=0.59$, $\mathrm{p}<0.0001) .{ }^{13}$ Although studies performed in the immediate postnatal period are likely to pick up many cases of postnatal blues, Dennis and McQueen ${ }^{14}$ found that mothers with an EPDS score $>12$ at 1 week postnatal were significantly more likely at 4 and/or 8 weeks to discontinue breastfeeding, be unsatisfied with their infantfeeding method, experience significant breastfeeding problems and report lower levels of breastfeeding self-efficacy.

Studies looking at the sex ratio at birth have shown that there is a strong gender bias in India, favouring boys. ${ }^{15-17}$ Jayachandran and Kuziemko ${ }^{18}$ have shown that boys tend to be breastfed longer. The EPDS score in relation to sex of the child has not been studied. Also the association between birth of girl babies (in a society with a male sex bias), EPDS score soon after birth and EBF has not been examined previously. We hypothesise that there may be a higher EPDS score and less exclusive early breastfeeding of girl children. Recognition of these possible barriers to EBF may allow more focused support to mothers that will promote breastfeeding and improve survival of the girl baby.

\section{Ethics statement}

Informed written consent was obtained from participants. Data and names of the respondents are kept confidential. The paper we propose to publish does not contain any identifying information, so no response the patients made can be attributed to any of the participants in the study.

\section{MATERIALS AND METHODS}

This was an observational cross-sectional study conducted between August 2010 and July 2011, at St Stephen's Hospital, Delhi. Only mothers delivering normally with their babies roomed-in were invited to participate. Mothers who consented to participate were interviewed on each of the first 2 days after delivery to enquire about breastfeeding. The weight and sex of the baby, mother's education, history of previous births and socioeconomic status were recorded.

Mothers were administered EPDS on day $2 .{ }^{19} \mathrm{~A}$ Hindi translation of the EPDS was administered to mothers
Table 1 International Standard Classification of Occupations (ISCO)-88 major groups and skill level ${ }^{22}$

Major group ISCO skill levels

1. Legislators, senior officials and managers

2. Professionals 4th

3. Technicians and associate 3rd professionals

4. Clerks 2nd

5. Service workers and shop and 2nd market sales workers

6. Skill agricultural and fishery 2nd workers

7. Craft and related workers 2nd

8. Plants and machine operators and 2nd assemblers

9. Elementary occupations 1st

0 . Armed forces

who preferred Hindi. ${ }^{20}$ This translation has been back translated and validated previously. ${ }^{21}$ The outcomes measured were EBF in the first $48 \mathrm{~h}$ and PND on EPDS.

Socioeconomic status was assigned grades 1-5 taking into account the skill levels and formal education using the 'Major Groups and Skill Levels Classification' of University of Warwick (table 1). International Standard Classification of Occupations (ISCO)-88 skill level 4 is considered grade 1 of socioeconomic status (academic), skill level 3 - grade 2 (vocational), skill level 2 - grade 3 (short education and skilled), and those not working (or semiskilled/unskilled) - grade $4 .^{22}$

Education level was also graded as follows-grade 1: mothers who have not completed primary school education; grade 2: primary school graduates up to secondary school; grade 3: if they had passed up to higher secondary education; grade 4: college graduates and grade 5: mothers who have completed a postgraduate degree course.

Correlates of EBF were examined. The incidence of EBF in boys and girls was examined separately and also for primiparous mothers, separately from mothers who had had previous babies.

EPDS score in relation to sex of the child was also examined. Depression score above 11 on EPDS was considered as significant using a cut-off determined previously by Teissèdre. ${ }^{13}$ Pearson $\chi^{2}$ test was used to look for significance. OR and 95\% CI of EBF were calculated. For proportions, 95\% CI of the observed proportion is reported. Multiple regression analysis of correlates of EBF was also carried out. CI was calculated using the CIA software. ${ }^{23}$

\section{Sample size calculation}

We calculated that in order to get results that reflect the target population at the $95 \%$ CI with a margin of error of less than $2.5 \%$, we would need to interview 1537 mothers. ${ }^{24}$ 


\section{RESULTS}

During the study period 3466 babies were born at the hospital. There were only 792 girls for every 1000 boys. Among women delivering their first babies, there were 901 girls per 1000 boys. Among mothers delivering their second babies the sex ratio was 737 girls to 1000 boys. If first child was a girl the ratio in the second delivery fell to $632: 1000$, but if the first child was a boy the sex ratio in second children was 841:1000.

In total, 1537 mothers of singleton babies were enrolled in the study. The sex ratio in the study sample 797 girls per 1000 boys was similar to the sex ratio of overall deliveries. In total, 1026 mothers in the study group were exclusively breastfeeding their babies.

Babies with a birthweight $2.5 \mathrm{~kg}$ or heavier were more likely to be exclusively breastfed compared with those less than $2.5 \mathrm{~kg}$ (low birthweight; $68.2 \%$ vs $59.8 \%$, $\mathrm{p}<0.01$; figure 1). Multiparous mothers were more likely to be exclusively breastfeeding than primiparous mothers $(71.6 \%$ vs $62.8 \%$, difference $=0.089,95 \%$ CI 0.042 to 0.135$)$.

EBF was significantly higher among mothers of boys as compared with those of girls $(70.8 \%$ vs $61.5 \%, \mathrm{p}<0.001$; figure 2). Gender of the baby had less influence on EBF of firstborn children. In total, $64.3 \%$ of primi boy babies and $61 \%$ of primi girl babies were exclusively breastfed $(\mathrm{p}=0.32)$. If the firstborn was a girl and the second baby was also a girl, $60 \%$ of the second children were exclusively breastfed compared with $77.3 \%$ if the second child was a boy $(p=0.05)$. The chances of exclusively breastfeeding the baby were highest if there was a boy sibling in the family, $78.6 \%$ compared with $67.9 \%$ if there was no boy in the family $(\mathrm{p}<0.01$; table 2$)$.

No significant difference in $\mathrm{EBF}$ was found related to maternal age, socioeconomic status, maternal education and working status.

The EPDS score was significantly higher in mothers giving birth to a girl child (mean EPDS score 6.0 \pm 3.39 compared with 5.4 $\pm 2.87, \mathrm{p}<0.01$ ). The depression score was significantly lower in mothers with at least one male child when compared with those with no male child $(5.21 \pm 3.25$ vs $5.9 \pm 3.2, \mathrm{p}<0.01$; table 2$)$. Significantly more mothers of girl babies had an EPDS score higher

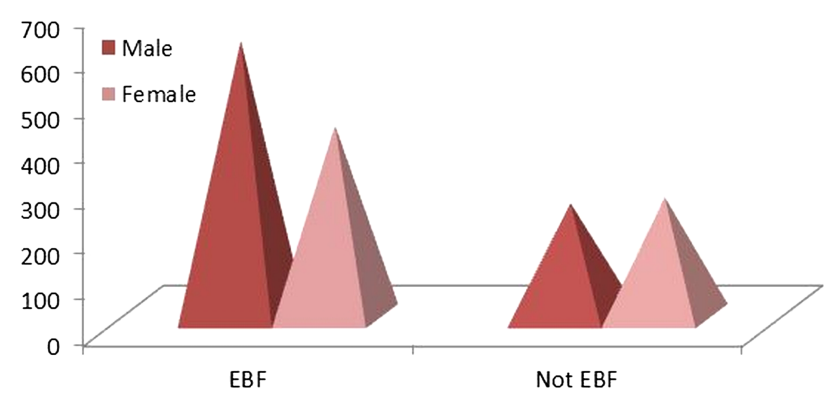

Figure 1 Breastfeeding and birthweight (EBF, exclusive breastfeeding). than 11 compared with mothers of boys $(9.7 \%$ vs $5.4 \%$, difference in proportion $=-0.045$, CI -0.072 to -0.019 ).

Higher EPDS score is associated with EBF rates. Only $52.4 \%$ mothers with a score $\geq 11$ were exclusively breastfeeding compared with $67.8 \%$ in those with a score $<11$ $(\mathrm{p}<0.01$; figure 3$)$.

Multiple logistic regression analysis indicated that birth of a female baby (OR=0.69, 95\% CI 0.56 to 0.87 ), high EPDS score $(\mathrm{OR}=0.53,95 \%$ CI 0.36 to 0.80$)$ and low birthweight ( $\mathrm{OR}=0.72,95 \%$ CI 0.55 to 0.95$)$ are associated with lower odds of EBF. This analysis suggests that sex of the baby, EPDS score and birthweight are significant independent factors influencing EBF.

\section{DISCUSSION}

Low female-to-male sex ratio is used as an index of sex bias in a community and can result from antenatal sex screening and selective abortion of female babies. ${ }^{25}$ In India, the male:female sex ratio is $914: 1000$. Sex ratio at birth is a better index of antenatal sex selection than the overall sex ratio. ${ }^{20}$ Previous studies have shown that sex ratio was particularly low in second children if the first was a girl. ${ }^{17} 26$

The same phenomenon was seen again in the fresh cohort studied here. The sex ratio in second order deliveries was 792 girls to 1000 boys but it was 632:1000 when the first child was a girl.

There was a male bias in breastfeeding too. More boys were being exclusively breastfed than girls. Jaychandran and Kuziemko hypothesise that since breastfeeding inhibits postnatal fertility, a mother might limit the nursing of an infant if she wants to continue having children. Mothers of girl children may want a boy soon and so may limit the duration of their feeding. ${ }^{18}$ Kimani $e t a l^{27}$ also found sex of the child to be one of the factors for suboptimal breastfeeding in Kenya $(n=4299)$.

\section{Gender of the baby and PND}

Our study found that depression score was higher in mothers of girls. The influence of gender of the baby on PND in mothers has been reported before. Adewuya et $a l^{28}$ in a study on Nigerian women found female sex

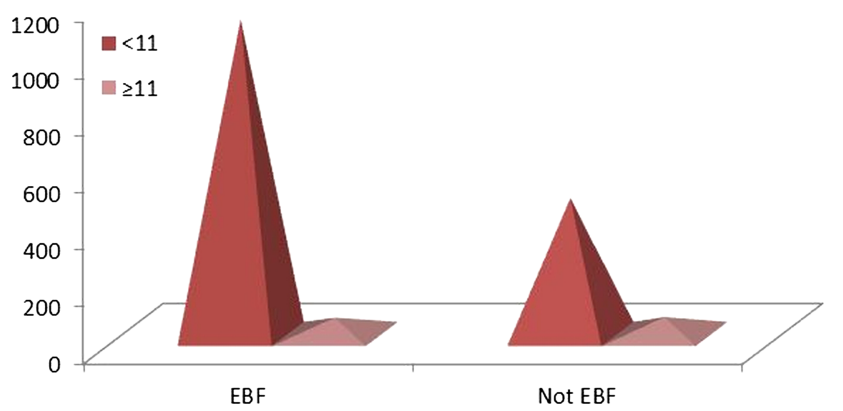

Figure 2 Breastfeeding and sex of the child (EBF, exclusive breastfeeding). 
Table 2 Birth order two or more

\begin{tabular}{lllrlll}
\hline Characteristic & EPDS $($ mean \pm SD) & p Value & No EBF & EBF & p Value & OR (95\% Cl) \\
\hline Male sibling & $5.21 \pm 3.52$ & & $52(26.8)$ & $191(38.9)$ & & 1.00 \\
No male sibling & $5.9 \pm 3.2$ & $<0.01$ & $142(73.2)$ & $300(61.1)$ & $<0.01$ & $0.58(0.40$ to 0.83$)$ \\
\hline EBF, exclusive breastfeeding; EPDS, Edinburgh Postnatal Depression Scale.
\end{tabular}

of the baby was one of the predictors for PND (OR 2.74, CI 1.87 to 4.03$)$. Chandran et $a l^{29}$ in Tamil Nadu, south India, showed that birth of a daughter, when a son was desired, was an important risk factor for depression. In a study of women in Iran also, gender of the child was found to be an important factor contributing to PND. ${ }^{30}$ Mothers who conceive a female fetus have higher levels of $\beta$-human chorionic gonadotropin. This along with other similar hormonal changes may be a biological explanation for the child's gender to affect PND. ${ }^{31} 32$ However this has not been elucidated clearly as yet.

Our study of EPDS was carried out on the second day after delivery. Mothers with low EPDS score could be those with postnatal blues and not all of them will have persistent PND. Only follow-up study will identify those with persistent PND. Our study protocol aimed at investigating early breastfeeding did not examine the issue of long-lasting depression in mothers of girl children.

\section{PND and breastfeeding}

We found that mothers with higher EPDS score were less likely to be exclusively breastfeeding. The effects of PND on EBF have been reported earlier. Dennis and McQueen ${ }^{33}$ also found that mothers with an EPDS score $>12$ at 1 week postnatal were significantly more likely at 4 and/or 8 weeks to discontinue breastfeeding, be unsatisfied with their infant-feeding method, experience significant breastfeeding problem and report lower levels of breastfeeding self-efficacy. In a cohort of 1745 Australian women it was found that the median duration of breastfeeding was 26 weeks for women with early-onset depression, 28 weeks for women with late-onset depression and 39 weeks for women without depression. ${ }^{34}$ Dennis and McQueen ${ }^{33}$ found maternal depression to be associated with delayed initiation and Ip $e t a l^{8}$ found its association with early discontinuation of breastfeeding.

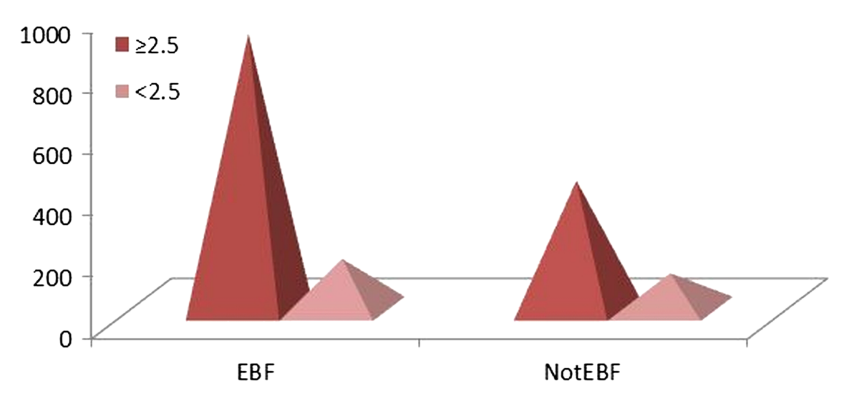

Figure 3 Breastfeeding and postnatal depression (EBF, exclusive breastfeeding).
The birth of a girl child is associated with greater depression, and lower EBF in girls could be mediated by depression. To examine the effects of depression on EBF we studied EBF in mothers of girls who had a high EPDS score against those with a low score. We found that in mothers of girls with a higher depression score, only $47.7 \%$ were exclusively breastfeeding compared with $63 \%$ with low depression levels (difference in proportion $=0.154,95 \%$ CI -0.26 to -0.028 ; table 3$)$. To look at the influence of sex of the child on EBF independent of associated depression, we performed multiple logistic regression analysis which showed that female sex of the child was independently associated with lower odds of EBF even after adjusting for depression. The comparison between the female OR in table 4 $(0.66)$ and the one in table 5 (0.69) suggests that controlling for PND and birthweight does not affect the gender difference in EBF much.

The results point to a pro-male gender bias. Mothers of girls may need more help to overcome PND and for improving breastfeeding rates. This in turn could enhance the survival of girl children and improve the sex ratio in the country.

This study does suffer from some shortcomings in as much as it was carried out in an urban hospital catering mostly to a middle-class clientele. The findings on sex ratio may therefore not be generalisable to other social groups. Studies in other populations are needed to confirm our findings.

We studied EBF in the first $48 \mathrm{~h}$. More studies are needed to elaborate the effect of sex bias on the duration of breastfeeding.

We studied the EPDS score in mothers within $48 \mathrm{~h}$ of delivery. Many of those with high scores may be suffering from postnatal blues rather than full-fledged PND. Further studies performed later in the postnatal period need to be carried out to examine how many of these mothers with high initial scores have longer lasting PND. Although multiple regression analysis shows that

Table 3 Breastfeeding by EPDS and sex of child

Characteristic EBF in males EBF in females $p$ Value
EPDS $<11 \quad 583 / 815(71.5 \%) \quad 389 / 617$ (63.0\%) 0.001

EPDS $\geq 11 \quad 23 / 40(57.5 \%) \quad 31 / 65(47.7 \%) \quad 0.33$

EBF, exclusive breastfeeding; EPDS, Edinburgh Postnatal Depression Scale. 
Table 4 Table showing correlates of exclusive breastfeeding and postnatal depression

\begin{tabular}{|c|c|c|c|c|c|c|}
\hline \multirow[b]{2}{*}{ Characteristic } & \multirow[b]{2}{*}{ EPDS (mean $\pm S D)$} & \multirow[b]{2}{*}{ p Value } & \multicolumn{4}{|c|}{ Exclusive breastfeeding } \\
\hline & & & No $(\mathrm{N}=511)$ & Yes $(\mathrm{N}=1026)$ & p Value & OR $(95 \% \mathrm{Cl})$ \\
\hline \multicolumn{7}{|l|}{ Maternal age (years) } \\
\hline$<25$ & $5.8 \pm 2.96$ & 0.25 & $171(36.4)$ & 299 (63.6) & 0.16 & 1.00 \\
\hline $25-29$ & $5.5 \pm 3.17$ & & 237 (33.3) & $474(66.7)$ & & $1.14(0.90$ to 1.46$)$ \\
\hline $30-34$ & $5.8 \pm 3.35$ & & $84(28.6)$ & $210(71.4)$ & & 1.43 (1.04 to 1.96$)$ \\
\hline$\geq 35$ & $5.3 \pm 2.71$ & & $19(30.6)$ & $43(69.4)$ & & 1.20 (0.73 to 2.29$)$ \\
\hline \multicolumn{7}{|l|}{ SES } \\
\hline Academic & $5.2 \pm 3.12$ & $<0.001$ & $79(32.4)$ & $165(67.6)$ & 0.86 & 1.00 \\
\hline Vocational & $5.2 \pm 2.87$ & & $109(35.4)$ & 199 (64.6) & & 0.87 (0.61 to 1.25$)$ \\
\hline Short education & $5.5 \pm 3.07$ & & $130(33.2)$ & $261(67.8)$ & & 0.96 (0.68 to 1.35$)$ \\
\hline Skilled & $6.2 \pm 3.18$ & & 147 (31.8) & 315 (68.2) & & 1.03 (0.74 to 1.43$)$ \\
\hline Semi/unskilled & $5.8 \pm 3.42$ & & 45 (34.9) & $84(65.1)$ & & 0.89 (0.57 to 1.40$)$ \\
\hline \multicolumn{7}{|l|}{ Birthweight (kg) } \\
\hline$\geq 2.5$ & $5.5 \pm 3.18$ & $<0.01$ & $402(31.7)$ & $865(68.3)$ & $<0.01$ & 1.00 \\
\hline$<2.5$ & $6.1 \pm 2.98$ & & $108(40.1)$ & $161(59.9)$ & & 0.69 (0.53 to 0.91$)$ \\
\hline \multicolumn{7}{|l|}{ Maternal education } \\
\hline$<$ Primary & $6.8 \pm 4.14$ & $<0.01$ & $23(40.4)$ & $34(59.6)$ & 0.44 & 1.00 \\
\hline Up to secondary & $6.0 \pm 3.02$ & & 61 (33.3) & $122(66.7)$ & & 1.35 (0.73 to 2.49$)$ \\
\hline Higher secondary & $5.8 \pm 2.93$ & & $111(35.6)$ & $201(64.4)$ & & 1.22 (0.69 to 2.18$)$ \\
\hline Graduate & $5.5 \pm 3.03$ & & 226 (31.2) & 499 (68.8) & & 1.49 (0.86 to 2.59$)$ \\
\hline Postgraduate & $5.3 \pm 3.33$ & & $90(34.7)$ & 169 (65.3) & & 1.27 (0.71 to 2.29$)$ \\
\hline \multicolumn{7}{|l|}{ Working status } \\
\hline Yes & $4.9 \pm 3.07$ & $<0.001$ & $87(29.1)$ & $212(70.9)$ & 0.09 & 1.00 \\
\hline No & $5.8 \pm 3.11$ & & $423(34.2)$ & $813(65.8)$ & & 0.79 (0.60 to 1.04$)$ \\
\hline \multicolumn{7}{|l|}{ EPDS } \\
\hline$<11$ & - & - & $460(32.1)$ & 972 (67.9) & 0.001 & 1.00 \\
\hline$\geq 11$ & & & $51(48.6)$ & $54(51.4)$ & & 0.50 (0.34 to 0.75$)$ \\
\hline \multicolumn{7}{|l|}{ Sex of the newborn } \\
\hline Male & $5.4 \pm 2.87$ & $<0.001$ & $249(29.1)$ & $606(70.9)$ & $<0.001$ & 1.00 \\
\hline Female & $6.0 \pm 3.39$ & & $262(38.4)$ & $420(61.6)$ & & 0.66 (0.34 to 0.75$)$ \\
\hline \multicolumn{7}{|c|}{ Sex of the newborn-primi } \\
\hline Male & $5.7 \pm 2.68$ & 0.87 & $163(35.7)$ & $294(64.3)$ & 0.32 & 1.00 \\
\hline Female & $5.6 \pm 3.27$ & & $154(39.0)$ & $241(61.0)$ & & 0.87 (0.66 to 1.15$)$ \\
\hline No siblings & & 0.06 & 317 (37.2) & $535(62.7)$ & $<0.001$ & 1.00 \\
\hline $\mathrm{MM}$ & $4.9 \pm 3.49$ & & 17 (15.9.) & $90(84.1)$ & & 3.1 (1.83 to 5.36$)$ \\
\hline MF & $5.8 \pm 3.4$ & & $17(23.9)$ & $54(76.1)$ & & $1.9(1.07$ to 1.30$)$ \\
\hline FM & $5.4 \pm 3.59$ & & $24(22.6)$ & $82(77.4)$ & & 2.0 (1.26 to 3.26$)$ \\
\hline $\mathrm{FF}$ & $6.6 \pm 3.39$ & & $14(40.0)$ & $21(60.0)$ & & $0.89(0.45$ to 1.77$)$ \\
\hline$>2$ children & $5.8 \pm 3.14$ & & $122(33.3)$ & $244(66.7)$ & & $1.2(0.92$ to 1.53$)$ \\
\hline
\end{tabular}

higher depression score and female sex of the child are associated with lower odds of EBF, a causal relationship is not implied.

In India the sex ratio is affected by antenatal sex determination and sex-selective feticide. ${ }^{25}$ High rate of sexselective abortion may complicate the interpretation of results.
Contributors AJ conceived the research project with JP. AJ collected the data. VS helped with the analysis of data and statistics. PK and PT helped with the write-up and review of literature.

Funding This research received no specific grant from any funding agency in the public, commercial or not-for-profit sectors.

Competing interests None.

Ethics approval St Stephen's Hospital Ethics Committee.

Table 5 Multiple logistic regression analysis

\begin{tabular}{llllll}
\hline Bf & OR & SE & $\mathbf{Z}$ & $\mathbf{p}>\mathbf{l z l}$ & $\mathbf{9 5 \%} \mathbf{C l}$ \\
\hline Sex & 0.6900392 & 0.0761006 & -3.36 & 0.001 & 0.5559035 to 0.8565409 \\
High EPDS & 0.5326528 & 0.1094171 & -3.07 & 0.002 & 0.3561157 to 0.7967046 \\
Low birthweight & 0.719286 & 0.1005456 & -2.36 & 0.018 & 0.5469104 to 0.9459912 \\
\hline EPDS, Edinburgh Postnatal Depression Scale. & & &
\end{tabular}


Provenance and peer review Not commissioned; externally peer reviewed.

Data sharing statement Original mastersheet containing anonymised patient data is available with the author and can be provided to anyone requesting the same.

Open Access This is an Open Access article distributed in accordance with the Creative Commons Attribution Non Commercial (CC BY-NC 3.0) license, which permits others to distribute, remix, adapt, build upon this work noncommercially, and license their derivative works on different terms, provided the original work is properly cited and the use is non-commercial. See: http:// creativecommons.org/licenses/by-nc/3.0/

\section{REFERENCES}

1. American Academy of Paediatrics. Work group on breastfeeding Breastfeeding and the use of human milk. Pediatrics 1997; 100:1035-9.

2. Huffman SL, Zehner ER, Victora C. Can improvements in breast-feeding practices reduce neonatal mortality in developing countries? Midwifery 2001;17:80-92.

3. Sheehan D, Bridle B, Hillier T, et al. Breastfeeding outcomes of women following uncomplicated birth in Hamilton-Wentworth. Can $J$ Public Health 1999:90:408.

4. Anderson GC, Moore E, Hepworth J, et al. Early skin-to-skin contact for mothers and their healthy newborn infants. Cochrane Database Syst Rev 2003;(2):CD003519.

5. Unicef. Breastfeeding - the remarkable first hour of life. Malasia: Unicef, 2007. htpp://www.unicef.org/malaysia/Breastfeeding_First_ Hour of Life.pdf (accessed 27 Jun 2012).

6. Unicef. Baby friendly hospital initiative revised, updated and expanded for integrated care. New York: World Health Organization and UNICEF, 2009. http://www.unicef.org/nutrition/files/BFHI_2009 s4.pdf (accessed 27 Jun 2012).

7. McLearn KT, Minkovitz CS, Strobino DM, et al. Maternal depressive symptoms at 2 to 4 months post partum and early parenting practices. Arch Pediatr Adolesc Med 2006;160:279-848.

8. Ip S, Chung M, Raman G, et al. Breastfeeding and maternal and infant health outcomes in developed countries. Evid Rep Technol Assess 2007;153:1-186.

9. Thurgood S, Avery MA, LWilliamson L. Postpartum Depression (PPD). American Journal of Clinical Medicine 2009;6:17-22.

10. Melinda Smith MA, Segal J. Postpartum depression and the baby blue symptoms, treatment, and support for new moms. http://www.helpguide. org/mental/postpartum_depression.htm (accessed 10 Mar 2013).

11. Ottawa U. Postpartum depression. http://www.med.uottawa.ca/sim/ data/Depression_postpartum_e.htm (accessed 3 Oct 2013).

12. Murray D, Cox JL. Screening for depression during pregnancy with the Edinburgh Depression Scale (EPDS). J Reprod Infant Psychol 1990;8:99-107.

13. Teissèdre $F$, Chabrol $H$. Detecting women at risk for postnatal depression using the Edinburgh Postnatal Depression Scale at 2 to 3 days postpartum. Can J Psychiatry 2004;49:51-419.

14. Dennis CL, McQueen K. Does maternal postpartum depressive symptomatology influence infant feeding outcomes? Acta Paediatr 2007;96:590-4.

15. Nayar U. Doomed before birth: study of declining sex ratio in the age group 0-6 years in selected districts of Punjab and
Haryana. New Delhi: NCERT; Department of Women's Studies, 1995:287.

16. Sahni M, Verma N, Narula D, et al. Missing girls in India: infanticide, feticide and made-to-order pregnancies? Insights from hospital-based sex-ratio-at-birth over the last century. PLOS ONE 2008;3:e2224

17. Manchanda S, Saikia B, Gupta N, et al. Sex ratio at birth in India, its relation to birth order, sex of previous children and use of indigenous medicine. PLOS ONE 2011;6:e20097.

18. Jayachandran S, Kuziemko I. Why do mothers breastfeed girls less than boys? Evidence and implications for child health in India. Q J Econ 2011:126:1485-538.

19. Currie ML, Rademacher $R$. The pediatrician's role in recognizing and intervening in postpartum depression. Pediatr Clin North $\mathrm{Am}$ 2004;51:785-801.

20. Dubey C, Gupta N, Bhasin S, et al. Prevalence and associated risk factors for postpartum depression in women attending a tertiary hospital, Delhi, India. Int J Soc Psychiatry 2012;58:577-80.

21. Nagpal J, Dhar RS, Sinha S, et al. An exploratory study to evaluate the utility of an adapted Mother Generated Index (MGI) in assessment of postpartum quality of life in India. Health Qual Life Outcomes 2008;6:107.

22. Warwik Institiue For Employment Research. Major groups and skill levels ISCO 88 guide section 2. http://www2.warwick.ac.uk/fac/soc/ ier/research/links/isco88/english/s2/ (accessed 2 Jul 2012).

23. Confidence Interval Analysis (CIA) software. http://www.som.soton ac.uk/cia (accessed 10 Apr 2012).

24. Creative Research Systems. Sample size calculator. http://www. surveysystem.com/sscalc.htm\#one (accessed 12 Apr 2012).

25. Sharma BR, Gupta N, Relhan N. Misuse of prenatal diagnostic technology for sex-selected abortions and its consequences in India. Public Health 2007;121:854-60.

26. Jha P, Kumar R, Vasa P, et al. Low female [corrected]-to-male [corrected] sex ratio of children born in India: national survey of 1.1 million households. Lancet 2006;367:211-18.

27. Kimani-Murage EW, Madise NJ, Fotso JC, et al. Patterns and determinants of breastfeeding and complementary feeding practices in urban informal settlements, Nairobi Kenya. BMC Public Health 2011;11:396.

28. Adewuya AO, Fatoye FO, Ola BA, et al. Sociodemographic and obstetric risk factors for postpartum depressive symptoms in Nigerian women. J Psychiatr Pract 2005;11:353-8.

29. Chandran M, Thayan P, Muliyil J, et al. Post-partum depression in a cohort of women from a rural area of Tamil Nadu, India. Incidence and risk factors. Br J Psychiatry 2002;181:499-504.

30. Kheirabadi GR, Maracy MR, Barekatain M, et al. Risk factors of postpartum depression in rural areas of Isfahan Province, Iran. Arch Iran Med 2009;12:461-7.

31. Yaron $Y$, Lehavi O, Orr-Urtreger A, et al. Maternal serum HCG is higher in the presence of a female fetus as early as week 3 post-fertilization. Hum Reprod 2002;17:485-9.

32. Hendrick V, Altshuler LL, Suri R. Hormonal changes in the postpartum and implications for postpartum depression. Psychosomatics 1998;39:93-101.

33. Dennis CL, McQueen K. The relationship between infant-feeding outcomes and postpartum depression: a qualitative systematic review. Pediatrics 2009;123:e736-51.

34. Henderson JJ, Evans SF, Straton JA, et al. Impact of postnatal depression on breastfeeding duration. Birth 2003;30:175-80. Erratum in: Birth $2004 \cdot 31: 76$. 